\title{
A EDUCAÇÃO FÍSICA NO ENSINO MÉDIO OU PARA ENTENDER A ERA DO GELO
}

\author{
Vicente Molina Neto' \\ Denise Grosso da Fonseca ${ }^{2}$ \\ Lisandra Oliveira e Silva ${ }^{3}$ \\ Rodrigo Alberto Lopes ${ }^{4}$ \\ Elisandro Schultz Wittizorecki ${ }^{5}$
}

\section{RESUMO}

Neste ensaio buscamos discutir a conjuntura que leva às recentes reestruturações no Ensino Médio brasileiro, assim como as tensões que historicamente estiveram em jogo nas disputas pelas finalidades desta etapa da escolarização e suas implicações para a Educação Física. Concluímos encaminhando argumentos para pensarmos a Educação Física que temos e a que queremos.

Palavras-chave: Educação Física. Ensino Médio. Currículo.

1 Doutor em Filosofia e Ciências da Educação. Professor da Escola de Educação Física, Fisioterapia e Dança da Universidade Federal do Rio Grande do Sul (ESEFID/UFRGS). Porto Alegre/Rio Grande do Sul, Brasil.

E-mail: vicente.neto@ufrgs.br

2 Doutora em Educação. Professora da Escola de Educação Física, Fisioterapia e Dança da Universidade Federal do Rio Grande do Sul (ESEFID/UFRGS). Porto Alegre/Rio Grande do Sul, Brasil. E-mail: dgf.ez@terra.com.br

3 Doutora em Ciências do Movimento Humano. Professora da Escola de Educação Física, Fisioterapia e Dança da Universidade Federal do Rio Grande do Sul (ESEFID/UFRGS). Porto Alegre/Rio Grande do Sul, Brasil. E-mail: lisgba@yahoo.com.br

4 Doutorando em Ciências do Movimento Humano. Professor da Rede Marista de Ensino - Colégio Pio XII (Novo Hamburgo/RS) e da Rede Municipal de Ivoti/RS. Porto Alegre/Rio Grande do Sul, Brasil.

E-mail: rodrigolopes11@gmail.com

5 Doutor em Ciências do Movimento Humano. Professor da Escola de Educação Física, Fisioterapia e Dança da Universidade Federal do Rio Grande do Sul (ESEFID/UFRGS). Porto Alegre/Rio Grande do Sul, Brasil.

E-mail: elisandro.wittizorecki@ufrgs.br 


\title{
PHYSICAL EDUCATION IN HIGH SCHOOL OR TO UNDERSTAND THE ICE AGE
}

\begin{abstract}
In this essay we seek to discuss the conjuncture that leads to the recent restructurings in Brazilian High School, as well as the tensions that have historically been at play in the disputes for the purposes of this stage of schooling and its implications for Physical Education. We conclude by referring arguments to think about Physical Education that we have and what we want.
\end{abstract}

Keywords: Physical Education. High School. Curriculum.

\section{LA EDUCACIÓN FÍSICA EN LA EDUCACIÓN SECUNDARIA O PARA COMPRENDER LA EDAD DEL HIELO}

\section{RESUMEN}

En este ensayo se discute la coyuntura que lleva a las recientes reestructuraciones en la Educación Secundaria brasileña, así como las tensiones que históricamente han estado en juego en las disputas por los fines de esta etapa de la escolarización y sus implicaciones para la educación física. Concluimos apuntando argumentos para reflexionar sobre la Educación Física que tenemos y la que deseamos.

Palabras clave: Educación Física. Educación Secundaria. Curriculum.

\section{INTRODUÇÃO}

Publicada no Diário Oficial da União no 184-A do dia 23 de Setembro de 2016, seção 1, a Medida Provisória (MP) no 7466 , de 22 de Setembro de 2016, instituiu, além de outras providências complementares,

[...] a Política de Fomento a Implementação de Escolas de Ensino Médio em Tempo Integral, altera a Lei $\mathrm{n}^{\circ} 9.394$ de 20 de Dezembro de 1996, que estabelece as diretrizes e bases da educação nacional, e a lei $n^{\circ} 11.494$, de 20 de junho, que regulamenta o Fundo de Manutenção e Desenvolvimento e de Valorização dos Profissionais da Educação [...] (BRASIL, 2016a).

Em uma tacada, o Governo Federal, do "alto" de suas prerrogativas constitucionais, atacou a estrutura da Educação Brasileira, propondo alterações no Ensino Médio e na destinação dos recursos a ele reservados. Um movimento muito rápido e sem discussão com a comunidade educativa e a sociedade em geral, ao ponto de entidades e

6 Medida provisória é uma providência legal editada pelo presidente da república sem a participação do poder legislativo, prevista constitucionalmente em situações de extrema relevância e urgência. O que parece não ser o caso da reforma do Ensino Médio, que carece de uma ampla discussão na sociedade civil organizada. 
representantes procedentes de distintas atividades e classes sociais manifestarem seu desconforto, contrariedade e constrangimento em relação à medida editada.

Compreender os efeitos dessa ação governamental agrega muitas dificuldades se a analisarmos em si mesma sem considerar o contexto sociopolítico e educacional em que opera, ou seja, as demandas de mercado da sociedade capitalista em sua mais recente versão, e ignorando a Proposta de Emenda Constitucional (PEC) 55 mara dos Deputados em 15 de junho de $2016^{8}$ (BRASIL, 2016b), que alterou, em claro retrocesso aos direitos constitucionais garantidos, as disposições constitucionais transitórias para instituir um novo regime fiscal ("congelamento" dos gastos primários do governo por 20 anos), desvinculando a receita das despesas e deixando de lado o debate educacional e acadêmico que antecede a MP plasmado no Plano Nacional de Educação (PNE) 20142034, Lei no 13.005, de 25 de junho de 2014 (BRASIL, 2014). Na MP n 746, a urgência que caracteriza a edição de uma MP foi contestada e ela in totum caracterizada como inconstitucional através da ação direta de inconstitucionalidade 5.599/DF proposta pelo Ministério Público Federal em 19 de Dezembro de 2016.

Outros projetos de lei em tramitação no Senado completam o "pacote de maldades" que retira o professor da relação pedagógica com os estudantes no contexto da escola, um exemplo é o Projeto de Lei do Senado (PLS) 193/2016 (BRASIL, 2016c), que propõe na Lei de Diretrizes e Bases (LDB) o Programa Escola sem Partido, cujo objetivo central é amordaçar o professor e eliminar o debate sócio-histórico e político dos conteúdos curriculares.

Um elemento central para a compreensão das proposições desse "pacote de maldades" está centrado na ruptura política recente na governabilidade do país alterada pelo conjunto de forças do parlamento. Há uma metamorfose nas relações de poder na condução do Estado brasileiro e a assunção desse conjunto de forças políticas redefine a hegemonia dos poderes da república e o protagonismo da cena política nacional. Com isso, no campo da Educação, o histórico dualismo ou darwinismo social no Ensino Médio retoma seu curso histórico sob a batuta das políticas públicas neoliberais orientadas ao mercado, havendo um recalque das políticas sociais em desenvolvimento por mais de uma década. Assim, a relação de confiança entre os agentes políticos e a sociedade brasileira é acometida de certo cinismo. Sloterdijk (2012) sublinha que a atitude cínica tem sua visibilidade acentuada em tempos de esperança política fracassada, transformando-se em uma mentalidade coletiva na qual os esperançosos e os desapontados disputam pretensões de verdade quanto aos discursos e ao esclarecimento.

7 No léxico político-sindical, também chamada de PEC da Maldade ou Emenda do Teto, que iniciou sua tramitação no parlamento brasileiro sob o número PEC 241.

8 Aprovada na Câmara dos Deputados pela base aliada do Governo Michel Temer com 366 votos contra 111 votos procedentes dos partidos de oposição e duas abstenções. No senado, a PEC 241/PEC 55 foi aprovada em segunda votação por 53 senadores da base de apoio político do governo contra 16 votos dos senadores oposicionistas. 


\section{CONCEPÇÕES CRÍTICAS DE LEITURA DO CENÁRIO: COMPREENDER PARA QUEM E COM QUE PROPÓSITO ESTA POLÍTICA ESTÁ OPERANDO}

Precisamos pensar, quando analisamos políticas, para além da agenda da Educação, especialmente em momentos históricos como o atual, quando políticas de orientação neoliberal e conservadoras encontram ressonância em diferentes extratos sociais e representam parte de um projeto maior. $\mathrm{O}$ redesenho radical da política educativa defendido pelo atual governo deve ser entendido, portanto, como "parte do plano", um elemento estratégico a respaldar e a legitimar o regime político-econômico que as elites se autorizam a defender para o país.

Abordagens eficazes para analisar o atual cenário, segundo Robertson e Dale (2011), precisam reconhecer, em primeiro lugar, que a Educação, na orientação econômica neoliberal, não é um empreendimento nacional. Ela está agenciada organicamente por interesses de atores e corporações não-governamentais transnacionais ligadas ao capital econômico mundial (Fundo Monetário Internacional (FMI), Banco Mundial (BM), Organização de Cooperação e de Desenvolvimento Econômico (OCDE)). Em decorrência disso, é fundamental a ampliação das escalas de análise e, do mesmo modo, uma reorientação de escopo para as pesquisas que realizamos. Recentes manchetes vinculadas a jornais de grande circulação do país explicitam, por exemplo, uma "cirúrgica" reaproximação em âmbito global do atual governo com o FMI (que vinha apenas atuando discretamente nos últimos anos) e, em escala nacional, com grandes empresários de diversos setores da indústria (idealizadores e financiadores de ação política que resultou no impedimento da presidente Dilma Rousseff).

A fórmula para promover a penetração deste discurso já é bastante conhecida, tendo sido inclusive utilizada pelo governo brasileiro na década de 1990. O esforço dos neoliberais, assim, é tratar de "provar" que o estado de bem-estar social não passa de uma quimera, que é incapaz de alcançar o que promete (justiça social e econômica, melhor distribuição de renda, políticas afirmativas). Declaram que os governos, quando dedicados a romper, mesmo que minimamente, com a lógica de acumulação capitalista, "quebram" o Estado por onerar-se com "privilégios injustificáveis" às classes subalternas. Soma-se a isso o discurso de que o Estado, ao envolver-se com aspectos considerados irrelevantes, uma vez que caberia a ele apenas preocupar-se com a Educação, Segurança e Saúde (Estado Mínimo), acaba por restringir a prática de liberdades individuais e econômicas.

O processo de implosão do estado de bem-estar social é feito em momentos de crise do capitalismo de modo oportunista. Cria, em um primeiro momento, um estado de crise para, posteriormente, apresentar soluções classificadas como duras, porém, urgentes e necessárias. Na nossa recente experiência, por exemplo, as justificativas para a implantação dos atrozes "pacotes de maldades" provieram de índices "maquiados" de crescimento do desemprego, da redução do valor do Produto Interno Bruto (PIB), da desconfiança dos mercados e, especificamente em relação ao sistema educativo, dos resultados insatisfatórios alcançados no último Índice de Desenvolvimento da Educação Básica (IDEB). Estes números, em seguida, são comparados de modo descontextualizado com os de nações 
onde já foram implantadas políticas da mesma ordem, criando, assim, um cenário com condições adequadas para que estas reformas ditas "impopulares" se justifiquem - que ironicamente, em nosso país, contam com um número significativo de apoiadores em todos os segmentos sociais.

Porém, na década de 1990, esse salvacionismo econômico não cumpriu o que anunciou. No âmbito educativo, as medidas econômicas foram insuficientes para alcançar números dignos e indicadores de qualidade para a Educação. Recentemente, do mesmo modo, países da União Europeia como Espanha, Portugal, Irlanda e, em especial, a Grécia, foram sujeitados às chamadas políticas de austeridade (TROIKA), vendo ruir suas soberanias nacionais em nome da promessa de retomada do crescimento. Os resultados práticos dessas políticas, porém, têm se revelado pouco animadores na medida em que, em alguns casos, se percebeu um recrudescimento ainda maior destas economias já bastante fragilizadas.

Contudo, indo aos porões (VEIGA-NETO, 2012), vale dizer que movimentos de atravessamento político semelhantes não são algo inédito na história da Educação brasileira. A própria LDB (BRASIL, 1996), depois de discutida e sistematizada pela sociedade brasileira, em seu tempo de tramitação no Congresso, foi atravessada, após pedido de vistas, pelo substitutivo do antropólogo Darcy Ribeiro, educador e político que teceu no Brasil dos anos 80 do século passado, seguindo os passos de Anísio Teixeira, os fundamentos da Escola de Tempo Integral, desenvolvendo o projeto educacional Centros Integrados de Educação Pública. Para Anísio Teixeira, é importante sublinhar, na escola pública de tempo integral, a Educação Física, a Dança e as Artes, em conjunto com leitura, escrita e aritmética e as ciências, eram fundamentais para preparar os estudantes para sua pauta sócio-histórica.

Assim, os acontecimentos que ora testemunhamos, materializados em medidas e pautas autoritariamente impostas e que atingem os rumos desse nível de escolaridade, expressam uma ruptura com os documentos legais e pedagógicos que vinham sendo discutidos nos diversos segmentos da sociedade e que até então se mostravam comprometidos com a busca de um caminho que superasse a histórica dualidade e fragmentação da educação secundária brasileira. A pretensão, segundo McCarthy et al. (2011), é um reordenamento sistemático das prioridades do Estado, subordinando a democracia à acumulação capitalista, tornando-a um simulacro determinado pelos interesses do poder econômico. Todas as instituições democráticas tornam-se irrelevantes, sendo usadas de maneira flexível e negociável, como se houvesse uma espécie de "constitucionalização do neoliberalismo" (ROBERTSON; DALE, 2011). O sistema escolar, por exemplo, volta-se para o atendimento das necessidades do mercado seguindo a premissa de que "não há lugar para todos" e, sendo assim, o problema deixa de ser coletivo, passando assim a ser individual. Para Frigotto (2013), no interior dessa perspectiva, as competências ensinadas na escola passam a pretender garantir, quando muito, a empregabilidade, desde que estas competências sejam deliberadas e validadas pelo próprio mercado. Para o autor, “[...] o empregável tem a qualidade mercantil de ser flexível e permanecer com garantia de emprego apenas enquanto funcional ao seu empregador" (FRIGOTTO, 2013, p. 68). 


\section{BREVE PERSPECTIVA HISTÓRICA DO ENSINO MÉDIO NO BRASIL}

Historicamente, o Ensino Médio, no Brasil, tem se constituído em um nível de escolaridade de difícil enfrentamento diante dos diferentes aspectos que perpassam sua estrutura, suas concepções e suas funções no seio da escolarização.

No Brasil Colônia, período marcado por uma economia agrária e escravista, a educação secundária emerge com uma identidade propedêutica e humanística, sob a égide da educação jesuítica, com o único propósito de preparar as elites coloniais para a continuidade dos estudos na Europa. Ao longo de seu desenvolvimento, vai assumindo um caráter cambiante e dual, passando pelos diversos períodos que demarcam o país em tempos de Império e República. Entretanto, cabe-nos destacar que o Ensino Médio atravessa a história educacional brasileira servindo, prioritariamente, aos interesses das elites dominantes, cumprindo a função seletiva, excludente e discriminadora de uma educação para minorias privilegiadas. De acordo com Alves e Corsetti, no Brasil, "[...] a escola historicamente foi objeto de disputas, considerada como um importante meio para a propagação de ideologias dominantes, reflexo de um Estado permeado por elitismos, coronelismos e autoritarismos, em que a classe economicamente privilegiada continua possuindo a hegemonia" (ALVES; CORSETTI, 2015, p. 24).

Nesse sentido, a escola é concebida ora como preparação para a continuidade aos estudos, ora como preparação para o trabalho, assumindo diferentes matizes que forjam distintas possibilidades para o jovem brasileiro, em uma permanente disputa entre o acesso ao Ensino Superior e/ou a conquista de um espaço no campo profissional. Nessa perspectiva, para Kuenzer,

\footnotetext{
É esta dupla função: preparar para a continuidade de estudos e ao mesmo tempo para o mundo do trabalho, que lhe confere ambiguidade. Uma vez que esta não é uma questão apenas pedagógica, mas política, determinada pelas mudanças nas bases materiais de produção, a partir do que se define a cada época, uma relação peculiar entre trabalho e educação (KUENZER, 1997, p. 9).
}

Por outro lado, o processo histórico evidencia que a partir do Brasil Colônia diversas mudanças foram ocorrendo no âmbito da educação secundária, as quais evidenciam ser este nível educacional muito mais secundário, no sentido de ser acessório ou inferior, que no sentido da progressão educacional que lhe é atribuída.

O início da institucionalização do Ensino Médio ocorre com a Reforma Francisco Campos em 1932, na qual a organização curricular era fundamentalmente propedêutica, visando especificidades formativas de acordo com o segmento a ser dado na escolha do curso superior: área jurídica, área médica, área da construção ou área das ciências da educação. Cumpre-nos ainda mencionar que a referida legislação incluía exercícios de Educação Física obrigatórios para todas as classes (BRASIL, 1932).

Entretanto, de acordo com Kuenzer (1997), é com a Reforma Capanema, denominada Lei Orgânica do Ensino Secundário (BRASIL, 1942), que o Ensino Médio passa a 
ser estruturado como curso, com estudos regulares. Nessa legislação, a Educação Física é incluída como uma prática educativa obrigatória para todos os alunos, até a idade de vinte e um anos. Além da formação propedêutica, através dos cursos colegiais, a Reforma Capanema reforça a dualidade da formação secundária ao instituir as Leis Orgânicas do Ensino Industrial (1942), do Ensino Comercial (1943) e do Ensino Agrícola (1946), complementares à constituição do Serviço Nacional de Aprendizagem Industrial (SENAI) e do Serviço Nacional de Aprendizagem Comercial (SENAC), em resposta ao crescente desenvolvimento nas áreas industrial, comercial e agrária. Nessa perspectiva, fica demarcada a separação social e técnica do trabalho em um paradigma taylorista/fordista que se acentua no âmbito da economia brasileira. Ou seja, educação profissional para quem deve ser um mero executante de funções instrumentais e educação intelectual para quem continuará cumprindo funções de mando no conjunto das relações sociais.

A LDB 4024/1961 (BRASIL, 1961), ao ser promulgada, estabelece a equivalência entre as distintas formações de nível secundário para fins de ingresso no Ensino Superior. Entretanto, não supera a dualidade que mantém a hierarquia entre educação para a continuidade dos estudos e educação para o trabalho e que mantém as diferenças culturalmente instituídas que alimentam as desigualdades sociais estabelecidas pelo modelo econômico dominante.

Em 1971, a Lei 5692, instituída pelo governo ditatorial, cujo poder foi instalado através do golpe militar de 1964, estabelece outra identidade para o Ensino Médio. Não mais as duas vertentes equivalentes para fins de continuidade nos estudos, mas a obrigatoriedade da formação profissionalizante, concretizada no chamado ensino de $2^{\circ}$ grau. De acordo com Kuenzer, a proposta de Ensino Médio, fiel ao modelo político e econômico da ditadura, traduz pelo menos três grandes objetivos,

A contenção da demanda de estudantes secundaristas ao Ensino Superior, que havia marcado fortemente a organização estudantil no final da década de 1960; a despolitização do Ensino Secundário, por meio de um currículo tecnicista; a preparação de força de trabalho qualificada para atender às demandas do desenvolvimento econômico que se anunciava (KUENZER, 1997, p. 17).

A proposta implementada através dessa legislação cumpre muito bem os dois primeiros objetivos, de contenção da demanda dos jovens em fecundo processo emancipatório que emanava dos movimentos libertários do período e de amordaçamento da formação política juvenil, em consonância com a política de repressão instalada naquele período. Entretanto, não cumpre o terceiro objetivo, pois o projeto pedagógico se apresenta inadequado e sem estrutura física, material e humana para dar conta das necessidades educacional e técnica demandadas pelos desafios da realidade e pelas exigências do mercado.

Portanto, o embate que se trava ao longo dos anos evidencia os diferentes matizes da luta que se estabelece entre campos ideologicamente antagônicos em que a dualidade do Ensino Médio permanece corroendo as malhas do processo de democratização dessa etapa da escolaridade. A última LDB, Lei 9394/1996 (BRASIL, 1996), no seu artigo 22, 
parece pretender defender a indissociabilidade entre essas duas finalidades ao declarar que "a Educação Básica tem por finalidades desenvolver o educando, assegurar-lhe a formação comum indispensável para o exercício da cidadania e fornecer-lhe meios para progredir no trabalho e em estudos posteriores". Nesse sentido, concordamos com a seguinte colocação de Kuenzer:

\begin{abstract}
Esse conceito mais amplo de educação incorpora o conceito de trabalho, reconhecendo a sua dimensão pedagógica e a necessidade da educação escolar vincular-se ao mundo do trabalho e à prática social, uma vez que o fim da educação é preparar o cidadão para se constituir como humanidade participando da vida política e produtiva (KUENZER, 1997, p. 30).
\end{abstract}

As questões legais que historicamente foram conformando os rumos do Ensino Médio nos últimos anos passaram a ser enfrentadas através da intensificação das discussões e da implementação de novos documentos legislativos e pedagógicos, bem como de programas identificados com ideologias progressistas.

\title{
A CONTRAPOSIÇÃO DOS DISPOSITIVOS LEGAIS
}

O debate sobre as questões relativas ao Ensino Médio já vinha acontecendo na sociedade brasileira, em especial na comunidade educativa. Havia certa convergência entre os segmentos envolvidos no debate educacional em curso e de amplas parcelas das comunidades sobre questões pendentes e necessárias no Ensino Médio, entre elas, que este não vinha atendendo bem as demandas sociais e os interesses da comunidade, principalmente dos estudantes, e que a desejada terminalidade da Educação Básica no final do Ensino Médio não acontecia, ou seja, a formação profissional não era adequadamente promovida, além de que a qualidade do ensino não oferecia a formação humana dos estudantes, pois muito de sua formação específica não se conectava com o setor produtivo e não ajudava os estudantes a constituírem um projeto de vida. Estas razões dificultavam a permanência do estudante na escola e promoviam a evasão e a repetência no ensino, cujos índices constituíam-se em números e percentuais bem expressivos. A Associação Nacional de Pós-Graduação e Pesquisa em Educação e outras organizações de trabalhadores da Educação propunham a inclusão, na meta 3 do PNE, de objetivos específicos e estratégias, no sentido de "universalizar o atendimento escolar para toda a população de quinze a dezessete anos e elevar a taxa de matrícula no Ensino Médio para setenta por cento em 2016 e noventa por cento até 2020 nessa faixa etária" (ANPED, 2011, p. 36). Já na meta 6, essas Associações preconizavam a oferta de Educação em Tempo Integral para $50 \%$ das escolas públicas de Educação Básica até 2020. Lembremos, rapidamente, que são metas que aumentam os investimentos em Educação e Saúde, agora na "Era do Gelo".

Por conta desse debate, ouvindo o que diziam educadores e especialistas, o Conselho Nacional de Educação aprovou e fez circular a Resolução n 2, de 30 de janeiro de 
2012, contendo Diretrizes Curriculares Nacionais para o Ensino Médio (DCNEM) (BRASIL, 2012). Essas Diretrizes, apoiadas no artigo 35 da Lei 9394/1996, orientam as unidades escolares a organizarem seus projetos políticos-pedagógicos sob os seguintes princípios: a) consolidação e aprofundamento dos conhecimentos adquiridos no Ensino Fundamental, com um indicativo claro de continuidades dos estudos; b) preparação básica para o trabalho e para a cidadania do estudante, prevendo aqui a preparação para a continuidade do aprendizado e a adaptação às demandas do trabalho, levando em consideração o aperfeiçoamento contínuo; c) formação ética do estudante e seu aprimoramento como pessoa humana, possibilitando o desenvolvimento de sua autonomia intelectual e de seu pensamento crítico; d) compreensão dos fundamentos científicos e tecnológicos dos processos produtivos, relacionando teoria e prática.

Interessante sublinhar que as DCNEM assentam ênfase no trabalho e na pesquisa como princípios educativos e pedagógicos na formação integral do estudante. Além disso, a formação humana se complementava nessas Diretrizes pela integração do trabalho com a ciência, a tecnologia e a cultura, propondo a interdisciplinaridade como princípio orientador das práticas escolares. Na organização dos conteúdos obrigatórios, estava explícito o ensino da Língua Portuguesa, da Matemática, do conhecimento do mundo físico e social e da realidade social e política brasileira, o estudo da Arte, incluindo a Música, da Educação Física, da História do Brasil e da cultura e das raízes étnicas na formação do povo brasileiro, em especial, as raízes indígena, africana e europeia, da Educação Artística, da Literatura, da Filosofia e da Sociologia e de uma Língua Estrangeira Moderna.

No que tange a Educação Física, já estava estabelecida sua presença na Área das Linguagens, junto com Português e Língua Materna para as populações indígenas, Língua Estrangeira e as Artes em geral. Aqui, já aparecem alguns indicativos quanto à possibilidade de organização do Ensino Médio em 7 horas diárias, embora a carga horária prevista para o Ensino Médio regular fosse o mínimo de 2.400 horas, com a carga horária anual de 800 horas em 200 dias letivos, havendo prescrições específicas para Educação de Jovens e Adultos (EJA) e Educação Profissional e Tecnológica. Em outras palavras, o ensino passaria de 4 horas diárias para 7 horas diárias.

A partir das DCNEM, veio a edição da Portaria Ministerial n 1.140, de 22 de novembro de 2013, proposta pelo Ministro da Educação, cujo teor instituiu o Pacto Nacional pelo Ensino Médio e definiu diretrizes gerais, forma, condições e critérios para a concessão de bolsas de estudo e de pesquisa no âmbito do Ensino Médio Público, nas Redes Estaduais e Distrital de Educação (BRASIL, 2013), o que significava a concessão de bolsas de estudos para os profissionais da Educação como forma de valorização desses profissionais e estímulo a Formação Continuada dos professores. Como efeitos dessa ação, vieram distintos programas de inovação à docência e formação de professores, muitos em articulação com programas da Coordenação de Aperfeiçoamento de Pessoal de Nível Superior (CAPES) do $\mathrm{B}^{9}$. Do ponto de vista conceitual, aparece a noção da Educação Politécnica. Ainda havia,

9 Léxico utilizado por uma parcela de acadêmicos para referir-se aos programas de fomento e apoio à pesquisa e auxílios no Ensino Básico. 
não sem polêmica, o debate sobre as Bases Nacionais Comuns Curriculares, hoje em sua terceira versão concluída, e a avaliação do Conselho Nacional de Secretários de Educação (CONSED) e da União Nacional de Dirigentes de Educação (UNDIME).

A ruptura política entre os poderes da república no Brasil em 2016 ofereceu a possibilidade de uma nova ordem institucional e mudanças nas equipes gestoras das políticas públicas do Governo Federal. No Ministério da Educação, houve o retorno dos "policy makers" dos Parâmetros Curriculares Nacionais editados e instituídos como diretrizes curriculares nacionais para o Ensino Médio em 1998, 2000 e 2002, por meio da Resolução CNE/CEB nº 03 de 26 de junho de 1998 (BRASIL, 1998). Com isso, na pressa de apagar o legado de gestões anteriores, editou-se o pacote da Educação e, nele, a MP n 746, de 22 de setembro de 2016, que retira a obrigatoriedade no Ensino Médio dos Componentes Curriculares Artes, Educação Física, Sociologia e Filosofia. Porém, outras alterações foram significativas e os seus efeitos ainda não estão nítidos. É o que veremos adiante.

Uma dificuldade importante presente nos debates educacionais é a obtenção de certos consensos entre os segmentos envolvidos, tanto nos atos educativos, quanto na implementação de políticas publicas consequentes e de longo prazo. Mainardes (2006), revisitando textos de Stephen Ball, sociólogo inglês que para compreensão das políticas educacionais usa a noção de "Ciclo de Política", sublinha que um ciclo contínuo de políticas, estabelece três contextos no processo de formulação de uma política (contexto de influência, contexto de produção e contexto da prática). São contextos e âmbitos inter-relacionados, contínuos e não lineares. "Cada um desses contextos apresenta arenas, lugares e grupos de interesse e cada um deles envolve disputas e embates" (MAINARDES, 2006, p. 50). Esta reflexão nos sugere que os diferentes grupos de interesse e agentes políticos, em permanente disputa nas arenas macro e micropolítica, exortam o dissenso e estimulam interpretações particulares e sectárias da legislação e das normativas educacionais. Por outro lado, pesquisas que realizamos nos convidam a pensar que as políticas educacionais raramente são implementadas de modo uniforme nos diferentes contextos de prática, ou seja, cada comunidade educativa em seu contexto sociopolítico, levando em conta a micropolítica da escola, traduz as normas gerais macropolíticas para seu contexto particular. Muitas vezes, há semelhança nas traduções, mas não é raro encontrar traduções completamente diferentes. É por isso que encontramos, nos ambientes escolares, respostas diferentes e originais que desafiam as questões e normas elaboradas pelos gestores educacionais e "policemakers", fato que mostra a temeridade em propor reformas educacionais sem debate com a comunidade escolar, uma vez que a vida nas escolas é como um moinho que tritura muitas das ilusões idealistas das vanguardas esclarecidas.

No debate entre as vanguardas esclarecidas e os trabalhadores do chão da escola (FENSTERSEIFER, 2016), parece que quem perde são os profissionais comprometidos com uma Educação pública de qualidade, garantidora de um ensino de condições justas para a melhor formação humana, das subjetividades dos nossos estudantes e também trabaIhadores do futuro próximo. O professorado está sendo reduzido ao papel de executores de projetos alheios. O que queremos dizer, retomando, do mesmo modo, Stephen Ball e seu ciclo de políticas, é que neste primeiro ciclo, o da produção da política, a mesa 
de debates, da qual vem resultando as açodadas e elitistas políticas educativas, não tem absolutamente salvaguardado nenhum espaço para a ela sentarmos. Todas as cadeiras parecem hoje estar ocupadas por outros convidados: representantes e representações do capital financeiro mundial orientados por uma discursividade própria, amparada em um cínico e frágil equilíbrio interno de contradições particulares, na qual eclodem os interesses do neoliberalismo (estado mínimo, livre mercado, meritocracia constitucional) e os do neoconservadorismo (estado judicial-policialesco, defesa dos valores cristãos e da família, autoritarismo multifacetário). Esta aliança vem a forjar um "ponto nodal" (LACLAU; MOUFFE, 2015), construindo um "cavalo de batalha" contra um antagonista comum: o cidadão mais pobre, aquele que nos últimos anos pôde viver e vislumbrar (mesmo que de forma limitada e incompleta) condições sociais mais justas e cidadãs. Este cidadão é hoje visto como um beneficiário indigno, um beneficiário ilegítimo do escasso dinheiro público, aquele que vive às custas de um governo mal gerido, corrupto e populista. É contra este cidadão que se voltam as canetas, os acordos de gabinete. O amplo "pacote de maldades" que responsabiliza um grupo específico por uma questão que é global, também impõe medidas que atacam sumariamente este grupo, e não os grandes detentores de capital no país.

Porém, mesmo a alvissareira maioridade institucional que entendemos ter sido construída a ferro e fogo nas escolas nos últimos anos, na qual professores e estudantes, mesmo diante de diferentes condições adversas, no contexto de prática, criam táticas (CERTEAU, 2014) inspiradas em seus próprios cotidianos para trabalharem e inventarem-se, parece estar também sob a mira da "modernização" que o atual desgoverno pretende impor à Educação Brasileira. Isso ficou evidente na entrevista ${ }^{10}$ do atual Ministro da Educação, Mendonça Filho, concedida em 10 de outubro de 2016 ao programa televisivo "Roda Viva" na TV Cultura, que, quando perguntado pela professora Guiomar Namo de Mello (ex-Secretária Estadual de Educação de São Paulo - PSDB) se haviam formas de controlar os sempre corporativistas e resistentes professores, obrigando-os a executarem as premissas da MP ipse literis promulgadas, respondeu que sim, mediante alterações dos marcos regulatórios e uma profunda inspiração nos governos dessa grei partidária no Estado de São Paulo. É conveniente lembrar que esses governos sujeitaram os professores a políticas meritocráticas, baseadas em premiações e punições que, ao mesmo tempo, serviram para retirar direitos trabalhistas. Somado a isso, os professores passaram a ver controlado o seu planejamento com a adoção de apostilas e a implantação de sistemas de exames que os obrigam a treinar os alunos para obter resultados ao invés de desenvolver processos educativos que, de fato, garantissem um aprendizado. Parece ser esse o caminho que nos aguarda, igualmente, em escala federativa.

A maioridade institucional está em perigo, embora saibamos nós, professores e pesquisadores que trabalham e estudam a vida nas escolas (McLAREN, 1997), que este espaço é de geografia sinuosa, um ambiente ainda hostil à presença e influência inconteste destes grupos e interesses. Eles não conhecem o terreno, pois não costumam nele estar,

10 Disponível em < http://tvcultura.com.br/videos/56543_roda-viva-ministro-da-educacao-mendonca-filho.html > . Acesso em: 11 de janeiro de 2017. 
quanto mais ouvi-lo ou, ainda, entendê-lo. Como afirma Sarason (2003), os formuladores de políticas educativas pouco têm estado atentos ao que sabem os docentes, e essa continuará não sendo sua real intenção. A escola é um meio, ponto intermediário que antecede um fim muito mais amplo e obscuro do que uma "simples" mudança no ensinar-aprender. Eis aqui um maquiavelismo político.

Em nossa avaliação, a MP no 746 reforça o dualismo social na medida em que vincula a proposição legislativa e o discurso pedagógico aos objetivos de uma classe social interessada em manter a hegemonia do discurso e do aparato pedagógico. Bernstein (1996) mostra como a classe social atua seletivamente na distribuição do conhecimento na escola e nos mecanismos de controle simbólico sobre os estudantes e suas aprendizagens, o que se dá por meio do discurso pedagógico, da estrutura curricular ou do controle simbólico das aprendizagens dos estudantes. No caso brasileiro, pesquisadores da História da Educação, conforme já mencionado neste texto, vêm sublinhando que o Ensino Médio se diferenciou, por um lado, como um ensino propedêutico e introdutório à universidade para os extratos sociais privilegiados no contexto das relações sociais (profissões destinadas ao controle simbólico dos dispositivos e discursos) e, por outro, como um dispositivo destinado aos trabalhadores do setor produtivo (produção social de bens materiais). Assim, a $M P n^{\circ} 746$ acentua tal disposição ao abandonar a ideia de formação integral (mesmo que a explicite no inciso 5 do Art. 36 da LDB ${ }^{11}$ ) e trabalhar apenas no plano da Educação em Tempo Integral, aumentando o tempo de permanência do estudante nas escolas que, em sua maioria, carecem de condições materiais objetivas para tal fim. A Portaria 1.145, de 10 de outubro de 2016, do Ministério da Educação (2016d), em conformidade com a MP $n^{\circ} 746$, antecipa o fomento da Educação em Tempo Integral para 572 escolas e 247.400 alunos, ou seja, para 4\% dos 6.422.259 estudantes matriculados no Ensino Médio em 2015. Ajustar os meios às novas finalidades exigirá aumento de despesas para além dos índices inflacionários previstos na PEC 241.

A MP no 746 amplia de 4 para 7 horas o tempo de envolvimento do estudante no Ensino Médio (Parágrafo Único do art. 24). Isso significaria dizer: a) haveria a necessidade de realocar estudantes em escolas ainda inexistentes, visto que a maioria das escolas oferece o Ensino Médio em dois ou três turnos. Nesse caso, é indispensável a construção de novas escolas e a contratação de novos professores; b) se o estudante vai permanecer na escola por 7 horas, faz-se necessária a criação de refeitórios nas escolas e a contratação de serviços dessa natureza, bem como de trabalhadores. Sempre se pode dizer que a emenda prevê que o estudante pode realizar suas aprendizagens em outros ambientes, cursos fora da escola, admissão de pessoas com notório saber, almoço dos estudantes fora do ambiente escolar ou contratação de empresas de "catering industrial" para prover a alimentação, dentre outros. Nesse sentido, o anexo II da Portaria do Ministério da Educação (MEC) no 1.145 é um exercício de imaginação que dispõe sobre a infraestrutura das escolas para

11 "Os currículos do ensino médio deverão considerar a formação integral do aluno, de maneira a adotar um trabalho para a construção de seu projeto de vida e para sua formação nos aspectos cognitivos e socioemocionais conforme diretrizes definidas pelo Ministério da Educação" (BRASIL, 2016d). 
acolher os estudantes em regime de Educação em Tempo Integral e um exemplo da entrega da educação pública a "privataria" quando observa que "caso a escola não tenha cozinha, deverá apresentar alternativas para a terceirização da alimentação" (BRASIL, 2016d). Assim, é importante questionar: como assegurar a qualidade da educação nesses casos? Se os gastos públicos primários estão "congelados", como prover as condições materiais objetivas para que os estudantes permaneçam 7 horas envolvidos com suas aprendizagens em escolas em condições materiais precárias, com falta de professores e funcionários? E os salários, o que dizer?

No caso específico da Educação Física, a retirada de sua obrigatoriedade no Ensino Médio ${ }^{12}$ (um atraso impensável) reduz as oportunidades de acesso do estudante aos conteúdos da cultura corporal do movimento. Conspira contra a desejada autonomia dos estudantes para eleger, organizar e programar suas experiências corporais para além da vida escolar, sua educação para a saúde na vida adulta com qualidade e para o exercício do lazer consciente das condições e da conjuntura social, política, econômica e cultural que envolve o tempo livre e sua ocupação. Temos aí um extraordinário ataque à formação integral do cidadão com efeitos desmedidos nos valores éticos, estéticos e morais da juventude brasileira.

A MP n 746 também expõe os trabalhadores da Educação em geral, e o professorado de Educação Física em particular, a certas incertezas e perplexidades, uma vez que faz uma série de alterações importantes e remete o encaminhamento destas a outros dispositivos, especificamente para os Sistemas Estaduais de Educação e para a Base Nacional Comum Curricular, o que é bastante problemático, dado que os Sistemas Estaduais de Educação estão colapsados e a referida Base ainda está em construção. Por exemplo: o inciso 6, do art. 36, prevê 1200 horas para cumprimento da Base Nacional Comum Curricular da carga horária total do Ensino Médio, conforme a definição dos Sistemas de Ensino. No parágrafo único do art. 24, a MP prevê que o total de horas anuais do Ensino Médio passa a ser 1.400 horas, ou seja, 4.200 horas nos três anos, havendo 3.000 horas disponíveis para os "Amigos da Escola", para os "Sábios de Notório Saber", para o "Edunegócio" (Alimentação do Estudante, Livro Didático, Cursos e Capacitações de Curta Duração, dentre outros) e o "vale tudo" nos itinerários formativos específicos (linguagens, Matemática, ciências da natureza, ciências humanas e formação técnica profissional). Ou será possível contar com laboratórios técnico-eletrônicos e oficinas profissionais nas aproximadamente 28.000 escolas que oferecem Ensino Médio no território nacional?

A flexibilização, ao propor, ainda, que os estudantes escolham ao longo do Ensino Médio pela especialização em uma das áreas de conhecimento, retoma ideias pedagógicas e curriculares que imaginávamos superadas na agenda de produção das políticas educativas brasileiras. Para Bauman (2013), garantir a possibilidade de escolher ao homo eligens, ao

12 Durante a escritura desse artigo, em 30 de Novembro de 2016, a Comissão Mista composta de senadores e deputados liderados pelo relator após análise de mérito, alterou o texto-base da MP tornando obrigatório o ensino da Educação Física, das Artes e do Inglês como conteúdos obrigatórios no Ensino Médio, diferente do que propõe a Lei n 9394/96 (LDB) sobre a obrigatoriedade desse Componente Curricular em todas as etapas da Educação Básica. 
cidadão contemporâneo, trata-se de uma das promessas do neoliberalismo econômico. O engendramento dos processos clientelistas e econômicos na política e na economia é uma estratégia comum em governos com esta orientação. Aquele que decide e que assume individualmente a ambivalente tarefa de escolher, em muito se assemelha ao papel de consumidor, que acredita que o simples fato de deter desta condição, Ihe alça a alcunha de cidadão moderno.

O estudante, assim, ao necessitar ver-se "empreendedor de si mesmo" (McCARTHY et al., 2011), coloca-se na cruel situação, também, de "algoz de si mesmo", visto que é intrínseca à tarefa de decidir o ônus do consequente desapossamento. Ao decidir, nossos estudantes optam por tornarem-se vítimas das suas próprias escolhas, que julgam serem "conscientes", cúmplices da precarização da própria aprendizagem, autores intelectuais do desalinho entre as suas reais necessidades e as condições materiais para garantia destas a partir deste "novo-velho" Ensino Médio. Isso porque optam, do mesmo modo, por consequência, por aquilo que não será objeto de seu processo de escolarização, por privarem-se de visitar alternativas que desconhecem, mas que potencialmente também seriam capazes de suscitar formas de ser e de agir coerentes às suas expectativas individuais e coletivas agora ou no futuro. A responsabilização e a autoindulgência são os efeitos colaterais mais cínicos dessas políticas neoliberais, cujos alertas não se encontram nas bulas que o nosso atual desgoverno defende, propala ou comunica.

Tratando-se do itinerário das linguagens e supondo-se a possibilidade de oferta opcional da Educação Física, as 3.000 horas a que nos referimos abrem espaço para os convênios com clubes e escolinhas de iniciação esportiva, a entrada de atletas talentosos para ensinar esportes na escola e outras estratégias criativas destinadas a superar a ausência de conteúdo, professores e espaços escolares. Embora haja legislação específica para a atuação e formação dos profissionais da Educação no Ensino Básico (Decreto nº 8.752 de 09 de maio de 2016, que institui a Política Nacional de Formação dos Profissionais da Educação no Brasil), a nosso ver há um caminho aberto na MP nº 746 para a ampliação da iniciativa privada nos espaços escolares públicos e privados e para o apressamento da formação profissional no Ensino Médio, com efeitos, inclusive, para o Ensino Superior, quando se fala em aproveitamento de créditos do primeiro para o segundo.

Em termos de avaliação do Ensino Médio, é possível ver com clareza, na inclusão de processos de reconhecimento, avaliação e certificação dos conteúdos. Diz o inciso 17:

"Para efeito de cumprimento das exigências curriculares do Ensino Médio, os Sistemas de Ensino poderão reconhecer, a partir de regulamentação própria, conhecimentos, saberes, habilidades e competências, mediante diferentes formas de comprovação como: I - demonstração prática; II - experiência de trabalho supervisionado ou outra experiência adquirida fora do ambiente escolar; III - atividades de educação técnica oferecidas em outras instituições de ensino; IV - cursos oferecidos por centros ou programas ocupacionais; $\mathrm{V}$ - estudos realizados em instituições de ensino nacionais ou estrangeiras; e, VI - Educação a Distância ou Educação Presencial mediada por tecnologias" (BRASIL, 2016a). 
Em síntese, há um processo de flexibilização do Ensino Médio em que o governo, de modo inconsequente com suas responsabilidades com a juventude desse país, entrega essa importante etapa da formação humana para a iniciativa privada, já com demasiada presença na Educação Brasileira.

Nosso grupo de investigação, estimulado pela PROPOSTA PEDAGÓGICA PARA O ENSINO MÉDIO POLITÉCNICO E EDUCAÇÃO PROFISSIONAL INTEGRADA AO ENSINO MÉDIO (2011 - 2014) (RIO GRANDE DO SUL, 2010), uma política destinada a organizar o Ensino Médio sobre conceitos semelhantes aos existentes no Pacto Nacional do Ensino Médio, que antes fizemos referência, propôs, e está desenvolvendo, o Projeto de Pesquisa denominado "A Educação Física no Ensino Médio: estudos de casos na Rede Estadual de Ensino do Rio Grande do Sul". Os estudos de caso vêm mostrando que:

a) O envolvimento do professorado de Educação Física varia desde o desinteresse cético ("Vamos ver no que isso vai dar. Eu continuo dando minha aula de sempre") até o envolvimento criativo, multidisciplinar e epistemologicamente engajado ("A participação da Educação Física nos Seminários Integrados é uma possiblidade de ampliar a cultura corporal do movimento e a formação dos nossos alunos. Agora nós planejamos juntos").

b) A referida Proposta vem oferecendo possibilidades de alteração nas estratégias didáticas utilizadas pelos professores nas aulas de Educação Física, embora o esporte institucionalizado seja o conteúdo majoritário das aulas e práticas corporais como atividades rítmicas e expressivas e ginásticas tenham presença reduzida. Contudo, iniciativas inovadoras acontecem.

c) Os professores traduzem para o contexto da escola as propostas e os projetos pedagógicos procedentes da administração de acordo com sua experiência docente, sua participação na micropolítica da escola e idiossincrasias pessoais. Muitas vezes, há apropriação do léxico da reforma, sem que, de fato, mudem as práticas docentes.

d) O professorado tem dificuldades para desenvolver um processo de avaliação emancipatória nas aulas de Educação Física. A vontade de fazê-la encontra obstáculo na intensificação do trabalho docente, nas condições materiais objetivas e na falta de Formação Continuada, tanto do ponto de vista conceitual, quanto estratégico, para além da incorporação do léxico conceituado na proposta pedagógica.

e) A proposta do Ensino Médio Politécnico prevê planejamento coletivo, ações interdisciplinares e avaliação emancipatória, mas não há garantias, na escola, dessas condições objetivas para que o coletivo docente efetive ações correspondentes.

\section{A EDUCAÇÃO FíSICA QUE TEMOS E A QUE QUEREMOS: ENCAMINHAMENTOS POSSÍVEIS}

Cremos que a MP $n^{\circ} 746$ dá relevo a uma crise sem precedentes na Educação Física brasileira. Sustentados em evidências fáticas, reprovamos com fervor a retirada dos Componentes Curriculares Educação Física, Artes, Sociologia e Filosofia, antes obrigatórios 
por força da LDB em vigor, pois a Educação Integral significa oportunizar à juventude o acesso pleno ao conhecimento, às diferentes configurações da cultura construída e acumulada pela humanidade e à possibilidade de reflexão crítica responsável sobre os valores, o compartilhamento destes e a vida em comum, porquanto sua retirada indiscutível atenta, agride e mutila a formação humana da cidadania, em especial a da juventude brasileira. A palavra "crise" vem da origem grega "krisis", usada pelos médicos antigos para prever a possibilidade de cura, ou possibilidade de morte, como desfecho do corpo por eles medicado. Em outras palavras, decisão diante alternativas em conflito e excludente definição. Hoje, usamos como sinônimo de distúrbio funcional, desequilíbrio, mudança brusca, recessão, risco, perigo, dificuldades em nosso entorno. Antes, na raiz sânscrita, " $k r i$ " significava depurar, purificar...

Agora pensemos: de um lado, por anos a fio, a Educação Física, salvaguardada por dispositivos legais, estava presente como Componente Curricular obrigatório em todas as etapas da escolarização. Fizemos esforços intensos para legitimá-la do ponto de vista epistemológico e pedagógico. No âmbito pedagógico, não ultrapassamos o umbral de disciplina fundamental para a formação humana dos estudantes e estamos aquém de disciplinas tradicionais como Português e Matemática. Por outro lado, questionamos, ao longo do tempo, com frequência, salários, falta de material e falta de infraestrutura adequada para seu desenvolvimento. Embora aconteçam boas práticas pedagógicas e soluções criativas na Educação Física no Ensino Médio em todo o país, muitas vezes, esquecemo-nos de refletir e de questionar o que fizemos e ainda fazemos nas aulas quando elas não atendem as expectativas da comunidade educativa.

Sim, a permanência da Educação Física no Ensino Médio é desejável porque ela é fundamental para o desenvolvimento cognitivo e sócio-afetivo dos estudantes, para sua inclusão em todos os aspectos da vida social, para sua Educação em/para a saúde em todas suas dimensões e para a ampliação de seus horizontes culturais, éticos, estéticos e morais. Mas é preciso que nossas aulas concretizem tais finalidades, que, ao final de cada aula, possamos ter uma resposta afirmativa, concreta e especificada para a pergunta: o que aprendemos na aula de hoje? E que, ao final de cada trimestre letivo, estudantes e professores possam avaliar os efeitos dessa aprendizagem e avaliar a si mesmos com a seriedade que um Componente Curricular requer. A crise que o governo nos oferece nos agride, mutila a formação dos estudantes e causa danos irreparáveis. O agressor obcecado só revisará as decisões contidas na MP n 746 diante de intensa força popular e política. Entretanto, a crise pode ser um momento importante para que reflitamos sobre a formação universitária dos professores de Educação Física, sobre nossas práticas pedagógicas na escola e nossa contribuição para a experiência vivida pelos estudantes nesse ambiente e fora dele.

A Educação Física que temos no Ensino Médio precisa melhorar, mas o estado atual não é justificativa legítima para substituir sua condição de Componente Curricular obrigatório por programas e penduricalhos de caráter compensatório oferecidos pelo Governo Federal no segundo tempo escolar ou fora dele. É por isso que, alinhados como somos às vertentes pedagógicas críticas, não nos furtamos de, mais do que diagnosticar, inferir e contestar, igualmente assumindo, a partir da nossa experiência com investigações 
de caráter colaborativo, nosso compromisso em dizer como acreditamos e defendemos como deveria ser, qual seria a base para um modelo alternativo de ação (ROBERTSON; DALE, 2011). É por isso que, desde o reconhecimento das fragilidades da Educação Física que temos, urgem as nossas ações para pleitearmos a Educação Física que queremos. Como discutimos, ela não está no velho-novo Ensino Médio e, ainda, também não está no cotidiano das muitas escolas, no desinvestimento pedagógico que temos visto em nossas incursões recorrentes aos seus cotidianos. Encontra-se em um ponto intermédio entre os incipientes avanços democráticos que os nossos documentos legais vinham propondo (DCNEM, Base Nacional Comum Curricular), as experiências curriculares progressivas (Ensino Médio Politécnico, no caso do Rio Grande do Sul) e a emergência do reconhecimento das demandas dos contextos de prática, das escolas, dos seus atores e das suas prementes necessidades. Faz-se necessário e determinante, para os interesses da escola como bem público, resistir a este acinte, a este retrocesso de dimensões catastróficas, cujos impactos, infelizmente, são imprevisíveis, os quais, embora sejamos suficientemente hábeis para mensurar, ainda precisamos mostrar melhores condições para deter, mobilizar e replanejar. O fato é que, desprezando a ordem institucional e a legitimidade popular, o Governo Federal instalado em 31 de Agosto de 2016, através do Ministério de Educação, implementa em 23 de Dezembro 2016, com base na MP nº 746, a seleção de 523 escolas para materializar as reformas que pretende.

\section{REFERÊNCIAS}

ALVES, Aline Aparecida Martini; CORSETTI, Berenice. História do Ensino Médio no Brasil República: implicações e contradições. In: AZEVEDO, José Clóvis; REIS, Jonas Tarcísio (Orgs.). Ensino Médio: projetos em disputa. Porto Alegre: Editora Universitária Metodista IPA, 2015.

ANPED - Associação Nacional de Pós-Graduação e Pesquisa em Educação. Documento.

Por um Plano Nacional de Educação (2011-2020) como Política de Estado. Rio de Janeiro, 2011. Disponível em: < http://www.anped.org.br/sites/default/files/resources/ PLANO_NACIONAL_Portal.pdf > Acesso em: 10 out. 2016.

BAUMAN, Zigmunt. Sobre la educación en un mundo líquido: conversaciones con Ricardo Mazzeo. Barcelona: Paidós, 2013.

BERNSTEIN, Basil. A estruturação do discurso pedagógico: classe, códigos e controle. Petrópolis: Vozes, 1996.

BRASIL, Ministério da Educação. Decreto 21.241, de 14 de abril de 1932. Disponível em: < http://legislacao.planalto.gov.br/legisla/legislacao.nsf/Niw_Identificacao/dec\%20 21.241-1932? OpenDocument > . Acesso em: 3 out. 2016.

BRASIL, Senado Federal. Decreto Lei 4.244 de 9 de abril de 1942. Lei Orgânica do Ensino Secundário. Disponível em: < http://www.histedbr.fe.unicamp.br/navegando/ fontes_escritas/5_Gov_Vargas/decreto-lei\%204.244-1942\%20reforma\%20capanemaensino \%20secund\%E1 rio.htm >. Acesso em: 13 out. 2106. 
BRASIL, Presidência da República. Lei 4.024 de 20 de dezembro de 1961. Lei de Diretrizes e Bases da Educação Nacional. Disponível em: < http://www.planalto.gov.br/ccivil_03/ leis/L4024.htm > . Acesso em: 13 out. 2016.

BRASIL. Ministério da Educação. Lei no 9.394 de 20 de dezembro de 1996. Lei de Diretrizes e Bases da Educação Nacional. 1996.

BRASIL. RESOLUÇÃO CEB Nº 3, DE 26 DE JUNHO DE 1998. Institui as Diretrizes Curriculares Nacionais para o Ensino Médio. Conselho Nacional de Educação. Disponível em: < http://www.seduc.ro.gov.br/portal/legislacao/RESCNE003_1998. pdf >. Acesso em: 10 out. 2016.

BRASIL. Resolução no 2, de 30 de janeiro de 2012. Contendo Diretrizes Curriculares Nacionais para o Ensino Médio. Conselho Nacional de Educação. Disponível em: < http://pactoensinomedio.mec.gov.br/images/pdf/resolucao_ceb_002_30012012. pdf $>$. Acesso em: 10 out. 2012.

BRASIL, PORTARIA No 1.140, DE 22 DE NOVEMBRO DE 2013. Institui o Pacto Nacional pelo Fortalecimento do Ensino Médio e define suas diretrizes gerais, forma, condições e critérios para a concessão de bolsas de estudo e pesquisa no âmbito do ensino médio público, nas redes estaduais e distrital de educação. Disponível em: < http:// pactoensinomedio.mec.gov.br/images/pdf/portaria_1140_22112013.pdf >. Acesso em: 10 out. 2016.

BRASIL. LEI No 13.005, DE 25 DE JUNHO DE 2014. Aprova o Plano Nacional de Educação - PNE e dá outras providências. 2014. Câmara dos Deputados. Disponível em: < http://www2.camara.leg.br/legin/fed/lei/2014/lei-13005-25-junho-2014-778970publicacaooriginal-144468-pl.html > . Acesso em: 12 out. 2016.

BRASIL. Medida Provisória $n^{\circ}$ 746, de 22 de Setembro de 2016. Institui a Política de Fomento à implementação de Escolas de Ensino Médio em Tempo Integral [...] e dá outras providências. Diário Oficial da União. 2016a. Disponível em: < http://portal. mec.gov.br/index.php?option =com_docman\&view $=$ download\&alias $=48601-\mathrm{mp}$ 746-ensino-medio-link-pdf\&category_slug = setembro-2016-pdf\&ltemid = 30192 > . Acesso em: 12 out. 2016.

BRASIL. Proposta de Emenda à Constituição nº 241/2016. Altera o ato das Disposições Constitucionais Transitórias para instituir o Novo Regime Fiscal. Câmara dos Deputados. 2016b. Disponível em: < http://www.camara.gov.br/proposicoesWeb/ prop_mostrarintegra;jsessionid $=70 \mathrm{E} 06 \mathrm{~B} 53021 \mathrm{D} 8 \mathrm{~A} 706 \mathrm{E} 4 \mathrm{COBE} 252173876$.proposic oesWeb2 codteor $=1468431 \&$ filename $=P E C+241 / 2016>$. Acesso em: 12 out. 2016. BRASIL. PROJETO DE LEI DO SENADO n 193, de 2016. Inclui entre as diretrizes e bases da educação nacional, de que trata a Lei no 9.394, de 20 de dezembro de 1996, o "Programa Escola sem Partido". 2016c. Senado Federal. Disponível em: < https:// www25.senado.leg.br/web/atividade/materias/-/materia/125666>. Acesso em: 12 out. 2016.

BRASIL. Portaria n 1.145 , de 10 de Outubro de 2016. Institui o Programa de Fomento à Implementação de Escolas em Tempo Integral, criada pela Medida Provisória $\mathbf{n}^{\circ}$ 746, de 22 de setembro de 2016. Diário Oficial da União. 2016d. Disponível em: < http:// 
portal.mec.gov.br/index.php?option $=$ com_docman\&view $=$ download \&alias $=49121$ port-1145-11 out-pdf\&category_slug=outubro-2016-pdf\&ltemid $=30192>$. Acesso em: 12 de out. 2016.

CERTEAU, Michel de. A invenção do cotidiano: 1, Artes de fazer. 21.ed. Petrópolis: Vozes, 2014.

FENSTERSEIFER, Paulo Evaldo. Tensões e sínteses possíveis na Educação Física escolar. In: BINS, Gabriela Nobre; LOPES, Rodrigo Alberto; DIEHL, Vera Regina Oliveira (Orgs.). Educação Física na escola: entre demandas curriculares e experiências artesanais. Porto Alegre: ESEFID/UFRGS, 2016, p. 336-354.

FRIGOTTO, Gaudêncio. Política e gestão educacional na contemporaneidade. In: FERREIRA, Eliza; OLIVEIRA, Dalila Andrade (Orgs.). Crise da escola e políticas educativas. 2.ed. Belo Horizonte: Autêntica, 2013.

KUENZER, Acácia. Ensino Médio e Profissional: as políticas do Estado neoliberal. São Paulo: Cortez, 1997.

LACLAU, Ernesto; MOUFFE, Chantal. Hegemonia e estratégia socialista. São Paulo: Entremeios, 2015.

MAINARDES, Jefferson. Abordagem do ciclo de políticas: uma contribuição para a análise de políticas educacionais. Educação \& Sociedade, Campinas, v. 27, n. 94, p. 47-69, jan./abr. 2006.

McCARTHY, Cameron; PITTON, Viviana.; KIM, Soochul.; MONJE, David. Movimento e estase na reorientação neoliberal da educação. In: APPLE, Michael; AU, Wayne; GANDIN, Luís Armando (Orgs.). Educação Crítica: análise internacional. Porto Alegre: Artmed, 2011.

MCLAREN, Peter. A vida nas escolas: uma introdução à pedagogia crítica nos fundamentos da educação. 2.ed. Porto Alegre: Artes Médicas, 1997.

RIO GRANDE DO SUL. Proposta Pedagógica n 1, de 2011. Proposta Pedagógica Para O Ensino Médio Politécnico e Educação Profissional Integrada Ao Ensino Médio. Disponível em: <http://www.educacao.rs.gov.br/dados/ens_med_proposta.pdf > . Acesso em: 17 dez. 2015.

ROBERTSON; Susan; DALE, Roger. O Banco Mundial, o FMI e as possibilidades de educação crítica. In: APPLE, Michael; AU, Wayne; GANDIN, Luís Armando (Orgs.). Educação Crítica: análise internacional. Porto Alegre: Artmed, 2011.

SARASON, Seymour. El predecible fracaso de la reforma educativa. Barcelona: Octaedro, 2003.

SLOTERDIJK, Peter. Crítica da Razão Cínica. São Paulo: Estação Liberdade, 2012.

VEIGA-NETO, Alfredo. É preciso ir aos porões. Revista Brasileira de Educação, v. 17, n. 50, p. 267-492, maio-ago, 2012. Disponível em: < http://www.scielo.br/pdf/rbedu/ v17n50/v17n50a02.pdf $>$. Acesso em: 10 out. 2016. 